\title{
Falls and Fear of Falling among Persons Who Receive Housing Adaptations-Results from a Quasi-Experimental Study in Sweden
}

\author{
Gunilla Carlsson ${ }^{1, *}$, Maria H. Nilsson ${ }^{1,2} \mathbb{B}^{\mathbb{D}}$, Lisa Ekstam ${ }^{1}$, Carlos Chiatti ${ }^{1}$ and \\ Agneta Malmgren Fänge ${ }^{1}$ \\ 1 Department of Health Sciences, Lund University, Box 157, SE-221 00 Lund, Sweden; \\ maria_h.nilsson@med.lu.se (M.H.N.); lisa.ekstam@med.lu.se (L.E.); carlos.chiatti@med.lu.se (C.C.); \\ agneta.malmgren_fange@med.lu.se (A.M.F.) \\ 2 Memory Clinic, Skåne University Hospital, SE-214 28 Malmö, Sweden \\ * Correspondence: gunilla.carlsson@med.lu.se; Tel.: +46-46-222-18-16 \\ Academic Editor: Sampath Parthasarathy \\ Received: 30 August 2017; Accepted: 22 September 2017; Published: 29 September 2017
}

\begin{abstract}
While health might deteriorate through the ageing and disablement process, the impacts of disability can be reduced by adapting the environment. This study aimed to investigate the effects of applying a standardized research-based strategy to housing adaptation as compared to ordinary practice with respect to falls and fear of falling. Another aim was to investigate the overall effects of housing adaptations on fall-related outcomes over time. In total, 196 clients were included at baseline, with follow-up at 3 and 6 months after the housing adaptation was implemented. The only significant difference between the two approaches was identified with respect to fear of falling at 3 months after the housing adaptation, but not after 6 months. The number of clients reporting actual falls increased over time in both sites, whereas the number of reported near-falls decreased most in the intervention site, but without significant differences. Thus, the patterns of differences between the sites are inconsistent, as are the patterns of change in fall-related outcomes. An overall conclusion is that if the goal is to improve fall-related outcomes, housing adaptation should be complemented with other interventions preventing falls and explicitly address the clients' activity limitations. In addition, longer follow-up times are necessary.
\end{abstract}

Keywords: active ageing; frailty; home modification; intervention; disability; controlled trial

\section{Introduction}

Falls and fall-related accidents represent a major public health issue, accounting for $70 \%$ of all in-hospital treatment due to accidents in Sweden [1]. Among older people, falls can result in long-term disability, dependence on other people in terms of activities of daily life, participation restrictions [2-4], and reduced quality of life [5], as well as increased morbidity and mortality [6,7]. Consequently, falls contribute to increased societal costs [8], and considerable gains would be achieved with a decline in the number of falls and falls-related injuries, both for individuals and for society as a whole.

Most often people fall while being active, for example, when taking a walk or simply shifting body weight while doing other activities $[9,10]$. Large objects, stairs and steps, and surface contamination have been identified amongst the most common risk factors for falling [11]. People with disabilities are at a higher risk of injury from falls than those without a disability [12]. The risks of falling increase with age $[9,11]$ and about one-third of people over the age of 65 fall at least once annually [9]. The proportion of fall-related injuries in and around the home is higher for older people as compared to younger [11]. However, younger persons with disabilities also have an increased risk of falling (see, for 
example, [13]). In addition to age, the main predictors of injurious falls include gait problems, cognitive impairment, previous history of falls, medication use, and mood disorders such as depression [14,15]. Moreover, psychological consequences of falls, such as fear of falling, are common [16]. Fear of falling is an umbrella term that includes constructs such as fall-related self-efficacy, concerns about falling, and balance confidence. It is more greatly associated with female gender, low physical function, and the use of a walking aid [17] and is most prevalent among prior fallers [17,18]. People experiencing fear of falling tend to avoid doing activities [19] with subsequent risks for activity as well as participation restrictions.

In daily life, person-environment-activity interactions are constantly ongoing and changes in one of the components may impact on the others [20]. Changes in the home environment, for example, by means of a housing adaptation, may improve activity performance, reduce dependence on other people [21-24], and improve the usability of the home [21,25]. Moreover, housing adaptation can contribute to reducing falls and fall-related disability $[9,26]$, in particular, among people at higher risk of falling [9,24]. Housing adaptations have proved to be successful when forming a part of multicomponent falls reduction programs [23]. A housing adaptation is an individually-tailored intervention aimed at improving independence in the individual's own home by altering the physical environment, for example, by removing thresholds, installing grab bars, or rebuilding the home [27]. The majority of housing adaptations in Swedish municipalities are assessed, certified, and evaluated by occupational therapists. Most of the individuals receiving housing adaptations are older, with age-related health decline (see, for example, $[24,28,29]$ ), however, younger or middle-aged people with acute or progressive diseases or injuries are also among the recipients of the intervention (see, for example, [26,29]).

Systematic approaches to housing adaptation management are used to some extent [30], but the majority of housing adaptations are implemented without making use of current evidence, applying unstructured methodology [31,32]. The Swedish housing adaptation legislation states that the aim is to facilitate an independent lifestyle for those with disability in their own home. No details are provided, however, on how to assess needs and the extent of housing adaptation required, etc. [27]. In addition, research on different approaches for housing adaptations is rare. Accordingly, this study aimed to investigate the effects of applying a standardized research-based strategy to housing adaptation as compared to ordinary practice on fall-related outcomes. The secondary aim was to investigate the overall effects of housing adaptations on fall-related outcomes over time.

\section{Materials and Methods}

\subsection{Study Design and Study Context}

This study is part of a quasi-experimental trial with a non-equivalent control group that had a before-after design [33], called the Research Strategy for Housing Adaptation (ResHA) trial. At the intervention site, occupational therapists applied an intervention that consisted of a standardized research-based strategy for housing adaptation management. At the control site, the occupational therapists worked according to their ordinary practice routines for housing adaptation management. In this trial, we hypothesized that, compared to ordinary practice, applying a research-based strategy on occupational therapy management of housing adaptations, including systematic assessment and evaluation, would positively affect relevant client outcomes.

Three municipalities in the south of Sweden were included based on the number of inhabitants, their geographical dispersion, and their similar organizational structures for housing adaptation administration. Medium-sized municipalities (approximately 40,000-50,000 inhabitants) were consecutively asked to participate in the study. Because of the project's complexity, duration and the effort required, the staff members and the management needed to express a sincere interest in participating in the study. In addition, a readiness to change their practices was a prerequisite to become an intervention municipality. Two of the municipalities accepted to become the intervention 
site and in order to include as many in the control site as in the intervention site, one municipality was asked and accepted to become the control site. Before the study started in 2013, there was a variation in the number of accepted housing adaptation errands granted in the three municipalities (between 3.4-10.5 per 1000 inhabitants, i.e., around 137-446 per year in each municipality) [34].

Housing adaptation was defined according Swedish legislation [27], signifying that adaptation can be provided for those who experience declining functional capacity in order to eliminate physical environmental barriers in the home, thus promoting independence and safety. Housing adaptation is a publicly-funded intervention in Sweden, administered by a given municipality in response to a person's application. The full costs of the housing adaptations are granted based on needs assessment and certification by a health professional, most often an occupational therapist employed by the municipality [34].

All non-institutionalized persons above 20 years of age who applied for a housing adaptation grant (via one of the occupational therapists employed in any of the three municipalities, around 45 occupational therapists) were considered eligible to participate in the study. All municipalities used the same inclusion and exclusion criteria. Exclusion criteria were living in sheltered housing and an inability to communicate or follow instructions in Swedish.

\subsection{Sample}

In total, a consecutive sample of 580 persons met the inclusion criteria to participate in the study (Figure 1). Poor health was not an exclusion criterion, but it turned out that 131 persons were judged by the occupational therapist as unable to participate due to poor health. Six additional persons were excluded due to other reasons, for example, the housing adaptation was urgent and performed before the first interview. The remaining 443 individuals were invited to participate, but 202 (46\%) declined. Out of the 202 persons, $64 \%$ were women. The average age was 80 years and $40 \%$ were 85 years or older. In total, 241 persons accepted to participate, but 45 of them had their housing adaptation application rejected. Therefore, the final study sample consisted of 196 clients at baseline (intervention (I): $n=90$, control (C): $n=106), 163$ after three months (I: $n=71 ; \mathrm{C}: n=92$ ), and 143 after 6 months (I: $n=65 ; \mathrm{C}: n=77)$.

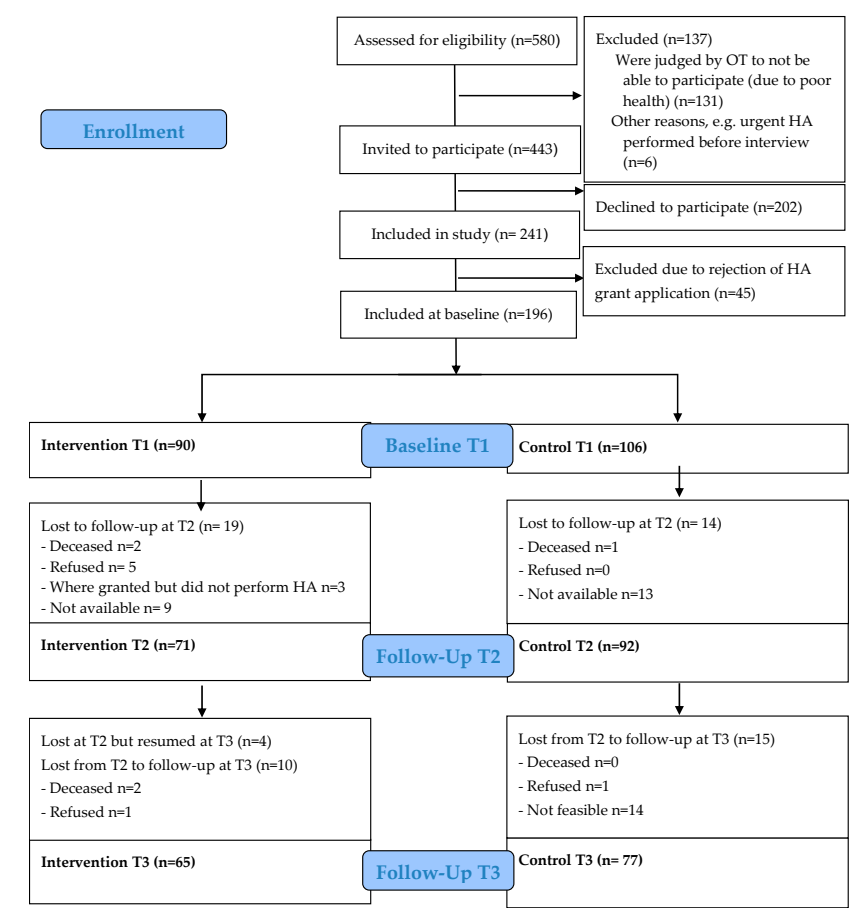

Figure 1. Consort flow chart for the trial. 
About two-thirds of the sample were women and $22 \%$ were aged 85 years or older (Table 1 ). The only statistical significant difference between the intervention and control municipalities was in cognitive function. However, more than one-third had missing data in relation to cognitive functioning; this occurred since the clients did not want to participate or did not complete the assessment.

Table 1. Characteristics of the sample included in the Research Strategy for Housing Adaptation (ResHA) study.

\begin{tabular}{|c|c|c|c|c|c|c|c|}
\hline & \multicolumn{2}{|c|}{$\begin{array}{c}\text { T1-Total Sample } \\
(n=196)\end{array}$} & \multicolumn{2}{|c|}{$\begin{array}{l}\text { Intervention Sites } \\
\qquad(n=90)\end{array}$} & \multicolumn{2}{|c|}{ Control Site $(n=106)$} & \multirow{2}{*}{$p$} \\
\hline & $n$ & $\begin{array}{c}\% \text { or mean } \\
\quad \pm S D\end{array}$ & $n$ & $\begin{array}{c}\% \text { or mean } \\
\pm \mathrm{SD}\end{array}$ & $n$ & $\begin{array}{l}\% \text { or mean } \\
\quad \pm S D\end{array}$ & \\
\hline Gender & & & & & & & 0.780 \\
\hline - Men & 72 & $37 \%$ & 34 & $38 \%$ & 38 & $36 \%$ & \\
\hline - Women & 124 & $63 \%$ & 56 & $62 \%$ & 68 & $64 \%$ & \\
\hline Age & & & & & & & 0.314 \\
\hline$-\quad \leq 64$ & 29 & $15 \%$ & 15 & $17 \%$ & 14 & $13 \%$ & \\
\hline$-65-74$ & 37 & $19 \%$ & 22 & $24 \%$ & 15 & $14 \%$ & \\
\hline - $75-84$ & 82 & $42 \%$ & 34 & $38 \%$ & 48 & $45 \%$ & \\
\hline$-\quad \geq 85$ & 44 & $22 \%$ & 17 & $19 \%$ & 27 & $26 \%$ & \\
\hline - missing & 4 & $2 \%$ & 2 & $2 \%$ & 2 & $2 \%$ & \\
\hline Living arrangements & & & & & & & 0.549 \\
\hline - living alone & 113 & $57 \%$ & 52 & $58 \%$ & 61 & $58 \%$ & \\
\hline - living with others & 82 & $42 \%$ & 37 & $41 \%$ & 45 & $42 \%$ & \\
\hline - missing & 1 & $1 \%$ & 1 & $1 \%$ & 0 & $0 \%$ & \\
\hline Education (in years) & 189 & $9.7 \pm 3.2$ & 83 & $9.7 \pm 3.1$ & 106 & $9.6 \pm 3.2$ & 0.775 \\
\hline Dependent on walking aids ${ }^{a}$ & & & & & & & \\
\hline - outside the home & 137 & $70 \%$ & 60 & $67 \%$ & 77 & $73 \%$ & 0.363 \\
\hline - entrance & 132 & $67 \%$ & 57 & $63 \%$ & 75 & $71 \%$ & 0.336 \\
\hline - inside the home & 122 & $62 \%$ & 53 & $59 \%$ & 69 & $65 \%$ & 0.403 \\
\hline Dependent on wheelchairs ${ }^{\text {a }}$ & & & & & & & \\
\hline - outside the home & 63 & $32 \%$ & 36 & $40 \%$ & 27 & $25 \%$ & 0.046 \\
\hline - entrance & 43 & $22 \%$ & 24 & $27 \%$ & 19 & $18 \%$ & 0.175 \\
\hline - inside the home & 31 & $16 \%$ & 21 & $23 \%$ & 10 & $9 \%$ & 0.015 \\
\hline $\begin{array}{l}\text { Social activities outside with } \\
\text { others }\end{array}$ & & & & & & & 0.188 \\
\hline - never/yearly & 57 & $29 \%$ & 26 & $29 \%$ & 31 & $29 \%$ & \\
\hline - monthly & 55 & $28 \%$ & 29 & $32 \%$ & 26 & $25 \%$ & \\
\hline - weekly or daily & 79 & $40 \%$ & 31 & $35 \%$ & 48 & $45 \%$ & \\
\hline - missing & 5 & $3 \%$ & 4 & $4 \%$ & 1 & $1 \%$ & \\
\hline Social activities outside alone & & & & & & & 0.113 \\
\hline - never/yearly & 85 & $43 \%$ & 45 & $50 \%$ & 40 & $38 \%$ & \\
\hline - monthly & 19 & $10 \%$ & 8 & $9 \%$ & 11 & $10 \%$ & \\
\hline - weekly or daily & 85 & $43 \%$ & 32 & $36 \%$ & 53 & $50 \%$ & \\
\hline - missing & 7 & $4 \%$ & 5 & $5 \%$ & 2 & $2 \%$ & \\
\hline Cognitive impairment ${ }^{b}$ & & & & & & & $>0.001$ \\
\hline$-26-30$ & 48 & $24 \%$ & 26 & $29 \%$ & 22 & $21 \%$ & \\
\hline$-\quad 18-25$ & 87 & $44 \%$ & 50 & $55 \%$ & 37 & $35 \%$ & \\
\hline$-\quad 10-17$ & 13 & $7 \%$ & 7 & $8 \%$ & 6 & $6 \%$ & \\
\hline - missing & 48 & $25 \%$ & 7 & $8 \%$ & 41 & $38 \%$ & \\
\hline ADL dependence ${ }^{c}$ & 157 & $12.1 \pm 5.8$ & 71 & $12.2 \pm 6.7$ & 86 & $12.0 \pm 4.9$ & 0.554 \\
\hline $\begin{array}{l}\text { Number of functional } \\
\text { limitations }{ }^{\text {a }}\end{array}$ & 196 & $4.7 \pm 1.9$ & 90 & $4.5 \pm 1.9$ & 106 & $4.9 \pm 1.9$ & 0.107 \\
\hline
\end{tabular}

\subsection{Intervention}

In the interventional municipalities, occupational therapists employed by the municipality applied a standardized research-based practice strategy to the housing adaptations. The intervention guided the occupational therapists with standardized procedures for the assessment and evaluation of person-, activity-, and housing-related aspects at home visits (for details, see [33]). Initially, the occupational therapists attended an extensive training course which included how to conduct the structured assessment procedures by the use of standardized instruments. Assessments were performed prior to housing adaptation certification (T1). The occupational therapists also provided the clients with self-administered questionnaires addressing fear of falling, retrospective falls, and participation. 
Follow-up visits in their home took place 3 (T2) and 6 months (T3) after the housing adaptation was finalized.

In the control municipality, the occupational therapists did not receive any specific training on the strategy used in the intervention municipality. They continued to work according to their ordinary routines for housing adaptation management, i.e., the occupational therapist combined structured and non-structured assessments of the person-, activity-, and housing-related aspects at home visits, telephone interviews, and in interviews with relatives, staff, etc., tailored to the specific situation of each client [32]. All the clients who met the inclusion criteria and who agreed to participate in the study were contacted by a project administrator (i.e., a specifically trained occupational therapist), who collected corresponding data at home visits.

Client outcomes were identified using a comprehensive process. That is, outcomes were chosen based on current Swedish legislation governing housing adaptations [27], and the Swedish Planning and Building Act [41], as well as previous research on outcomes of housing adaptations [9,24,31]. In addition, outcomes were selected based on their close link to housing adaptations, i.e., the use of a mobility device.

\subsection{Assessments}

A history of falls [16] was assessed by using the dichotomous (yes/no) question: "In the last six months, have you fallen in such a way that your body hit the ground?" If the client responded yes, the client was asked to state the approximate number of falls. A dichotomous (yes/no) question concerned the history of near falls during the past 6 months; a near-fall was defined as "a fall initiated but arrested by support from a wall, railing, other person, etc." [42]. If the client responded yes, the client was asked to state the approximate number of near-falls.

Fear of falling was assessed by means of two different measures. First, the client answered a single dichotomous (yes/no) question: "Are you afraid of falling?" Thereafter, the short version of the Falls Efficacy Scale International (FES-I) [43,44] was used, which addresses concerns about falling. The short FES-I includes seven items (i.e., activities) with the following response categories (scored 1-4): "not at all concerned", "somewhat concerned", "fairly concerned", or "very concerned". An additional response option was also added in the current study: "unable/unwilling to reply". The total score ranges from 7 to 28 (higher scores = more concerned about falling).

For descriptive purposes, assessments included dependence in activities of daily living (ADLs), participation outside the home, and global cognitive functioning and functional limitations. Dependence in ADLs was assessed according to the ADL staircase [38-40], which has nine items and the following response categories: "independent without difficulties", "independent with difficulties", "partly dependent", and "dependent" (0-3). The total score ranges from 0-27.

Two study-specific questions addressed the frequency of participation outside home. The response categories were "almost never", "yearly", "monthly", "weekly", and daily". For analytical purposes, the variables were reclassified into three categories: "never/yearly", "monthly", and "weekly/daily".

As a global assessment for cognitive functioning the Montreal Cognitive Assessment (MoCA) was used [36,37]. The maximum score is 30 points ( 1 point is added if the person has 12 years of education or less, up to a maximum total score of 30 ), and 26 points and more indicates normal cognitive function.

To assess the number of functional limitations and use of mobility devices, the personal component sub-scale from the Housing Enabler [35] was used. The presence of twelve functional limitations (i.e., difficulty in interpreting information, visual impairment, blindness, loss of hearing, poor balance, lack of coordination, limitation of stamina, difficulty in moving the head, reduced upper extremity function, reduced fine motor skill, loss of upper extremity function, reduced spine and/or lower extremity function) and the use of walking aids or wheelchair were dichotomously assessed (yes/no). The two questions on dependence on mobility device were supplemented by a question on whether they used their mobility devices outside the home, in the entrance, or inside the home. 


\subsection{Data Analysis}

We first used both descriptive and inferential statistics to evaluate whether the sample differed significantly in the baseline socioeconomic and clinical characteristics between the intervention and the control sites. Counts and proportions were analyzed using chi-squared and Fisher's exact test where appropriate. Continuous variables were analyzed using Analyses of Variance (ANOVA) tests.

Data from the two follow-ups after 3 and 6 months was then analyzed. The time frame in the questions about history of falls and near-falls was the last 6 months, which means that 6 months had passed between T1 and T3, but there might be an overlap in reported results between T1 and T2 as well as between T2 and T3. The T2 data for these two questions were therefore not included in the analyses. For the analysis of the follow-ups, we aimed to evaluate differences between the two groups in the main fall-related outcomes. We investigated both differences between actual values and changes in the outcomes at the two follow-ups. We used chi-squared tests for differences at the different time points in proportions and ANOVA regressions for continuous variables. In addition, to evaluate the statistical significance of observed changes in proportions over time, we used the Stata module ptrend for analysis of proportions trends. Last, mixed-linear models were used for obtaining adjusted estimates of changes in the FES-I scores at different time points, adjusting for time of the assessment and FES-I baseline values. All analyses were done using STATA 14.0. For all tests, a statistical level of significance of 0.01 was defined in order to account for the small dimension of the sample and avoid the risk of false-positive results.

\subsection{Ethical Considerations}

After a client had contacted an occupational therapist regarding a housing adaptation errand, the occupational therapist in the intervention as well as in the control municipality asked the client whether he or she was willing to participate in the study. Participation was completely voluntary and after the clients had received oral and written information about the study, they provided written informed consent. If the person was cohabiting, the partner also received oral and written information about the study. Withdrawal or declined participation in the study did not affect further services. The study was approved by the Regional Ethical Review Board in Lund (2012/566).

\section{Results}

The final sample comprised 196 clients who actually received a housing adaptation in the study municipalities: 90 in the two intervention sites and 106 in the control site. Sixty-three percent of the sample were women, and less than $15 \%$ of them were below 65 years of age. The majority of the sample lived alone (58\%). The sample does not differ significantly between the two areas in terms of demographic, social, and clinical characteristics, except for their dependency on wheelchair use inside the home and for cognitive impairment level. With respect to the former characteristics, the significant difference between the two groups are mainly connected to the higher number of missing values among the sample in the control site (Table 1).

At baseline (T1), slightly more than half of the clients (53.6\%) reported that they had fallen during the last six months (Table 2). Roughly the same proportion of fallers can be found among the control and intervention municipalities. Six months after the housing adaptation (T3), the proportion of fallers increased up to $71.8 \%$ at the control municipality, whereas the proportion of fallers increased up to $55.4 \%$ in the intervention municipalities $(p=0.041)$. After six months (T3), the reported mean number of falls decreased from 2.2 (SD 5.5) down to 1.7 (SD 8.8), with a clearer drop among clients in the intervention group (here the mean changed from $2.4 \pm 5.5$ to $1.4 \pm 3.4$ ). Significant differences cannot be found between the two groups in terms of near-falls. At baseline, approximately $60 \%$ of the persons reported near-falls in both sites. With respect to the proportion of those reporting being afraid to fall, while no differences were observed at baseline, self-reported fear of falling was more prevalent at T3 among those in the intervention group as compared to the control group ( $82.8 \mathrm{vs.} 66.7 ; p=0.001$ ). 
Coherently with this, fear of falling measured using the FES-I was higher both at baseline (18.2 \pm 5.7 vs. $14.1 \pm 5.3 ; p<0.001)$, T2 (14.9 \pm 5 vs. $13.2 \pm 4.2 ; p=0.036)$, and T3 (16.1 \pm 4.9 vs. $13.2 \pm 4.7$; $p<0.001)$ among clients in the intervention group.

Table 2. Fall-related outcomes at baseline and follow-up at 3 and 6 months.

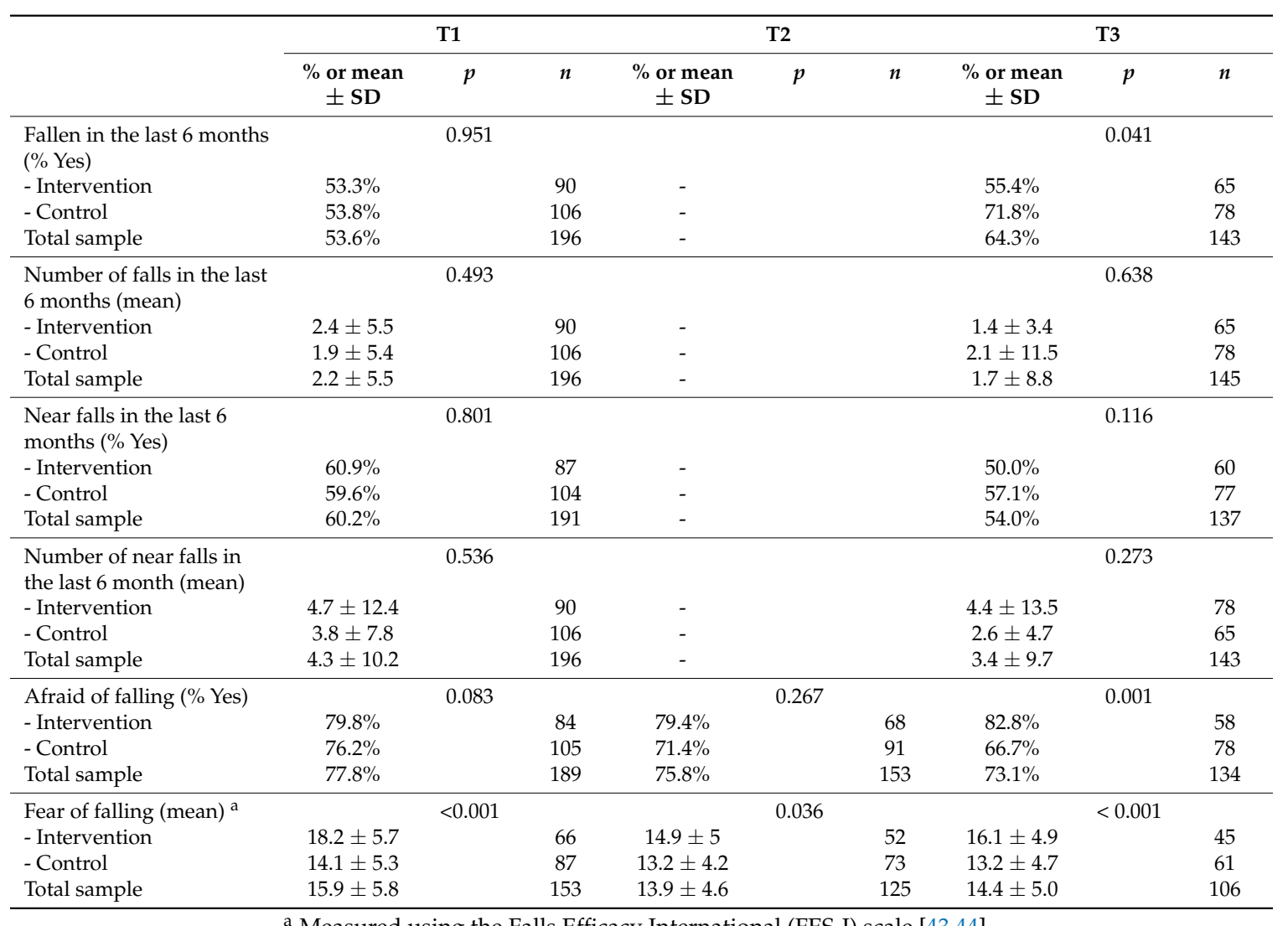

${ }^{a}$ Measured using the Falls Efficacy International (FES-I) scale [43,44].

With respect to the longitudinal changes in the fall-related variables, the analyses showed (Table 3) that the proportion of fallers increased by $10.8 \%$ between $\mathrm{T} 1$ and $\mathrm{T} 3$ (test for trend significance: $p=0.0473)$, with the larger increase observed among clients in the control group $(18 \% ; p=0.0131)$. Conversely, the proportion of near-fallers decreased by $6.2 \%$, with a larger reduction in the intervention group. The percentage of those reporting being afraid of falling decreased on average by $2 \%$ at T2 and $4.6 \%$ at $\mathrm{T} 3$, compared with $\mathrm{T} 1$ values, with no significant trends. The level of fear of falling measured using the FES-I, however, showed a marked reduction among the intervention group between T2 and $\mathrm{T} 1(-3.3 \pm 5.1$ vs. $-0.4 \pm 5.3 ; p=0.005)$ and a substantial stability between T2 and T3. Overall, fear of falling decreased in the sample by $1.1 \pm 5.5$, but no significant differences were found at T3 between the two groups. 
Table 3. Changes in fall-related outcomes between baseline and follow-up at 3 and 6 months.

\begin{tabular}{|c|c|c|c|c|c|c|c|c|c|}
\hline & \multicolumn{3}{|c|}{$\Delta \mathrm{T} 2-\mathrm{T} 1$} & \multicolumn{3}{|c|}{$\Delta \mathrm{T} 3-\mathrm{T} 2$} & \multicolumn{3}{|c|}{$\Delta \mathrm{T} 3-\mathrm{T} 1$} \\
\hline & $\begin{array}{l}\% \text { or Mean } \\
\quad \pm \text { SD }\end{array}$ & $p$ & $n$ & $\begin{array}{l}\% \text { or Mean } \\
\quad \pm \mathrm{SD}\end{array}$ & $p$ & $n$ & $\begin{array}{l}\% \text { or Mean } \\
\quad \pm \text { SD }\end{array}$ & $p$ & $n$ \\
\hline \multicolumn{10}{|l|}{$\begin{array}{l}\text { Fallen in the last } 6 \text { months } \\
\text { (\% Yes) }\end{array}$} \\
\hline - Intervention & - & - & - & - & - & - & $2.1 \%$ & 0.800 & 65 \\
\hline - Control & - & - & - & - & - & - & $18.0 \%$ & 0.013 & 78 \\
\hline Total sample & - & - & - & - & - & - & $10.8 \%$ & 0.047 & 143 \\
\hline $\begin{array}{l}\text { Number of falls in the last } \\
6 \text { months (mean) }\end{array}$ & & & & & & & & 0.512 & \\
\hline - Intervention & - & - & - & - & - & - & $-0.9 \pm 4.5$ & & 65 \\
\hline - Control & - & - & - & - & - & - & $0.1 \pm 11.4$ & & 78 \\
\hline Total sample & - & - & - & - & - & - & $-0.4 \pm 9$ & & 143 \\
\hline \multicolumn{10}{|l|}{$\begin{array}{l}\text { Near falls in the last } 6 \\
\text { months (\% Yes) }\end{array}$} \\
\hline - Intervention & - & - & - & - & - & - & $-10.9 \%$ & 0.189 & 60 \\
\hline - Control & - & - & - & - & - & - & $-2.5 \%$ & 0.739 & 78 \\
\hline Total sample & - & - & - & - & - & - & $-6.2 \%$ & 0.263 & 137 \\
\hline $\begin{array}{l}\text { Number of near falls in } \\
\text { the last } 6 \text { month (mean) }\end{array}$ & & & & & & & & 0.857 & \\
\hline - Intervention & - & - & - & - & - & - & $-1.0 \pm 19.4$ & & 65 \\
\hline - Control & - & - & - & - & - & - & $-1.1 \pm 7.5$ & & 78 \\
\hline Total sample & - & - & - & - & - & - & $-0.9 \pm 13.8$ & & 143 \\
\hline \multicolumn{10}{|l|}{ Afraid of falling (\% Yes) } \\
\hline - Intervention & $-0.4 \%$ & 0.958 & 84 & $3.3 \%$ & 0.504 & 68 & $3.0 \%$ & 0.680 & 58 \\
\hline - Control & $-4.8 \%$ & 0.449 & 105 & $-4.8 \%$ & 0.504 & 91 & $-9.5 \%$ & 0.155 & 78 \\
\hline Total sample & $-2.0 \%$ & 0.669 & 189 & $-2.7 \%$ & 0.603 & 153 & $-4.6 \%$ & 0.339 & 134 \\
\hline Fear of falling (mean) ${ }^{a}$ & & 0.005 & & & 0.228 & & & 0.094 & \\
\hline - Intervention & $-3.3 \pm 5.1$ & & 43 & $1.1 \pm 4.4$ & & 35 & $-2.4 \pm 5.3$ & & 35 \\
\hline - Control & $-0.4 \pm 5.3$ & & 68 & $0.0 \pm 3.7$ & & 51 & $-0.4 \pm 5.6$ & & 56 \\
\hline Total sample & $-1.5 \pm 5.4$ & & 111 & $0.4 \pm 4.0$ & & 86 & $-1.1 \pm 5.5$ & & 91 \\
\hline
\end{tabular}

At a multivariate level, when correcting for FES-I baseline value and time, the FES-I scores were slightly reduced at the intervention sites after three months, i.e., 2.1-points reduced mean score. There was no longer a statistical significant difference between the sites after six months (T3) (Table 4).

Table 4. Mixed-linear model-based estimates of change in the FES-I score.

\begin{tabular}{ccccc}
\hline \multirow{2}{*}{$\begin{array}{c}\text { Outcomes (Intervention } \\
\text { vs. Control) }\end{array}$} & \multicolumn{3}{c}{ Between-Group Difference } & \multirow{2}{*}{$\boldsymbol{p}$ value } \\
\cline { 2 - 3 } & Mean & $\mathbf{( 9 5 \% \text { Confidence Interval) }} n$ \\
\hline Assessment & & & & \\
T1 & 0.72 & -0.38 & 1.82 & 0.20 \\
T2 & -2.04 & -3.35 & -0.72 & $<0.001$ \\
T3 & 1.42 & -0.17 & 3.01 & 0.08 \\
\hline
\end{tabular}

\section{Discussion}

This study investigated whether a standardized research-based strategy to housing adaptation management had an effect on falls, near-falls, and fear of falling as compared to ordinary housing adaptation practice. The only significant difference between the two approaches could be identified for fear of falling at three months after the housing adaptation, but not in a 6-month perspective (Tables 3 and 4). This study also aimed to investigate the overall effects of housing adaptations on fall-related outcomes over time. The number of clients reporting actual falls increased over time in both sites, most in the control municipality $(18 \%)$, whereas the number of reported near-falls decreased most in the interventional municipalities $(10.9 \%)$, but without significant differences between the two sites. That is, the patterns of differences between the intervention and control sites are inconsistent, as is the pattern of change in the fall-related outcome variables. 
There are several plausible explanations to these inconsistent patterns. It might be that, even if the differences in characteristics between the groups were not significant, the clients in the intervention group used wheelchairs to a larger extent both indoors and outdoors already at baseline and they were also younger (Table 1). Given the fact that balance and mobility problems account for falls and risks of falling [45], the number of falls and near-falls is presumably lower among people using a stable mobility device such as a wheelchair compared to people using walking devices such as sticks or rollators, which were more common in the control group.

Another potential explanation for our findings may relate to our sample. We included clients eligible for housing adaptations, however, a history of falls and/or fear of falling were not inclusion criteria, and thus the study may be underpowered for detecting differences. Neither the housing adaptations were specifically focusing on reducing falls or fear of falling. Both the intervention and control groups received a housing adaptation and the goal of those usually involves a broader intention than solely fall-related outcomes, i.e., the clients should be able to live independently in their own home [27]. However, the housing adaptation might not correspond to the location and activity where the individual's falls occur, or where the circumstances that induce fear of falling are. Although the most common adaptations are related to mobility difficulties, such as removal of thresholds or installation of grab bars [34], other interventions are found that might not have a primary effect on falls, such as storage of mobility devices. In retrospect, it would probably have been advantageous to relate the dichotomous question of fear of falling to indoors and outdoors specifically.

Comparing standardized interventions with ordinary practice is a challenge, since components included in the standardized intervention may also to various extents be included in ordinary practice [46]. For example, the same kinds of assessments as applied in the standardized procedure may be included in ordinary practice as well. In this study, it would mean that there is a potential overlap between the intervention and control groups when it comes to assessments and follow-ups, thus potentially impacting on the outcomes.

The intervention in this study concerned occupational therapy practice and housing adaptation was just one part of the measures the occupational therapist suggested to enhance independent home living, due to additional client needs. A challenge with such an intervention aiming to affect client outcomes is the issue of the degree to which the occupational therapists in the intervention group used the results of the baseline assessments. Did they use the assessments in their housing adaptation decision process, or was the standardized research-based strategy in fact seen as something extra, of little relevance for practice? There is also the question of to what extent the occupational therapy team learnt something from the use of the strategy that they actually used or implemented in their ordinary practice, but these issues were not the focus of this paper. The provision of housing adaptations can be considered a complex intervention, since there are several interacting components, and among other issues, the length and complexity of causal chains linking intervention to outcome vary [46]. Even if it is difficult to standardize the design and delivery of complex interventions, this project was an attempt in that direction [33]. As acknowledged by the Medical Research Council (MRC) framework [46], the context in terms of organizational structure and climate has an impact on how research is used in practice, but also, as in this study, staff turnover might impact on how the occupational therapist as a team adopt the intervention. A follow-up period of 6 months might have been too short to evaluate the effects of the intervention on fall-related outcomes, since many fall-prevention interventions require follow-ups for over a year or longer because of delayed effects [16]. Also, the data collection of falls and near-falls were based on retrospective recall, which may result in underreporting of falls [47], however, this ought not to differ between the intervention and control municipalities. According to recommendations, one should use prospective daily recording as well as additional telephone or face-to-face interviews to rectify missing data [16]. Extensive logistics are, however, required to collect this type of data among the persons belonging to the target group of this study, and the clients might already feel stressed by the housing adaptation per se and by participating in the study. In order to reduce falls, multicomponent interventions seem to have an effect [23]. Besides environmental 
modifications, multicomponent interventions include exercise, and treatment of underlying diseases and impairments, etc. [9]. Fear of falling was also common $(77.8 \%)$ in our sample and previous research has shown that the prevalence of fear of falling ranges from $21 \%$ to as much as $85 \%$ among community-dwelling older adults [48]. In order to reduce fear of falling just like to reduce falls, exercise and/or multifactorial programs are required $[49,50]$. Besides assessments that explicitly address the clients' limitations in activity performance, our findings thus suggest that not only falls but also fear of falling should be acknowledged in clinical practice, and in future research addressing clients eligible for housing adaptations. Moreover, our findings further strengthen the support for complementing housing adaptations with other interventions, such as exercise or multifactorial programs in order to affect fall-related outcomes.

A common characteristic among housing adaptation clients is that their functional capacity is too low to overcome environmental barriers in the home in a safe way [51], but on the other hand, as persons in general, they differ in needs and interests. The fact that a housing adaptation might comprise several measurements and is not a uniform intervention should be kept in mind. The content and the magnitude differ, even if most of them result in limited adaptations such as threshold removal or installation of grab bars [34]. More detailed analyses of the specific interventions might also increase the knowledge about the clinical relevance.

\section{Additional Methodological Considerations}

In considering the limitations of this study, we have to mention the possibility of a selection bias, which might affect the generalizability of our results. The oldest population was less likely to participate in the study, potentially due to their frailer conditions. At the end, the participants over 85 years were sufficiently represented in our sample, however, caution should be exercised in this respect. Furthermore, the missing data of FES-I and MoCA (Tables 1 and 2) need to be reflected upon. We cannot exclude the possibility that some of the missing data of FES-I are in fact due to our amendment of an additional response option (i.e., "unable/unwilling to reply"), which was done in order to determine whether all questions were administered. In the short FES-I, the following is stated: "If you currently don't do the activity, please answer to show whether you think you would be concerned about falling IF you did the activity". Our amendment might have overruled this original instruction. The lesson learned is that one should be cautious when adding such a response option, since it might contradict instructions in the scale.

The MoCA may have been lacking for several persons in the control site due to the fact that project administrators, unknown to the clients, made the assessments. Assessments of this kind might be stressful and the clients might not have had the same confidence in the assessors as they have in their ordinary occupational therapist.

\section{Conclusions}

Although this standardized strategy in relation to housing adaptations showed a statistically significant short-term effect on fear of falling, it did not persist 6 months after the housing adaptation. Moreover, there were no statistically significant differences between the intervention and control site in relation to falls or near-falls. An overall conclusion is that if the goal is to affect falls and fall-related outcomes, housing adaptations should be complemented with other interventions preventing falls. Such future intervention studies should also explicitly address the clients' abilities to perform activities.

\section{Trial Registration}

\section{ClinicalTrials.gov: NCT01960582.}

Acknowledgments: This study was funded by the Swedish Research Council FORMAS and the Faculty of Medicine at Lund University. The study was based on data from a quasi-experimental study of housing adaptations in Sweden. It was accomplished within the context of the Centre for Ageing and Supportive 
Environments (CASE), Lund University, financed by the Swedish Research Council for Health, Working Life and Welfare, FORTE.

Author Contributions: Gunilla Carlsson, Maria H. Nilsson, and Agneta Malmgren Fänge designed and drafted the article. Lisa Ekstam coordinated the data collection. Carlos Chiatti performed the statistical analyses in dialog with all the authors. Gunilla Carlsson took responsibility for writing the paper and all the authors interpreted data and critically revised the article. Agneta Malmgren Fänge was the principal investigator of the project. All the authors approved the final version of the manuscript.

Conflicts of Interest: The authors declare no conflict of interest.

\section{References}

1. Swedish Agency for Health Technology Assessment and Assessment of Social Services, SBU. Omhändertagande av äldre Som Inkommer Akut Till Sjukhus-Med Fokus på SköRa äldre. En Systematisk Litteraturöversikt; Caring for elderly who arrive urgently to hospital—focusing on frail elderly people. A systematic literature review; Swedish Agency for Health Technology Assessment and Assessment of Social Services, SBU: Stockholm, Sweden, 2014; ISBN 978-91-85413-62-1. (In Swedish)

2. Collerton, J.; Kingston, A.; Bond, J.; Davies, K.; Eccles, M.P.; Jagger, C.; Kirkwood, T.B.; Newton, J.L. The Personal and Health Service Impact of Falls in 85 Year Olds: Cross-Sectional Findings from the Newcastle 85+ Cohort Study. PLoS ONE 2012, 7, e33078. [CrossRef] [PubMed]

3. Matsuda, P.N.; Shumway-Cook, A.; Ciol, M.A.; Bombardier, C.H.; Kartin, D.A. Understanding Falls in Multiple Sclerosis: Association of Mobility Status, Concerns About Falling, and Accumulated Impairments. Phys. Ther. 2012, 92, 407-415. [CrossRef] [PubMed]

4. Pin, S.; Spini, D. Impact of falling on social participation and social support trajectories in a middle-aged and elderly European sample. SSM Popul. Health 2016, 2, 382-389. [CrossRef]

5. Stenhagen, M.; Ekström, H.; Nordell, E.; Elmståhl, S. Accidental falls, health-related quality of life and life satisfaction: A prospective study of the general elderly population. Arch. Gerontol. Geriatr. 2014, 28, 95-100. [CrossRef] [PubMed]

6. Alamgir, H.; Muazzam, S.; Nasrullah, M. Unintentional falls mortality among elderly in the United States: Time for action. Injury 2012, 43, 2065-2071. [CrossRef] [PubMed]

7. Siracuse, J.J.; Odell, D.D.; Gondek, S.P.; Odom, S.R.; Kasper, E.M.; Hauser, C.J.; Moorman, D.W. Health care and socioeconomic impact of falls in the elderly. Am. J. Surg. 2012, 203, 335-338. [CrossRef] [PubMed]

8. Heinrich, S.; Rapp, K.; Rissmann, U.; Becker, C.; König, H.-H. Cost of falls in old age: A systematic review. Osteoporos. Int. 2010, 21, 891-902. [CrossRef] [PubMed]

9. Gillespie, L.D.; Robertson, M.C.; Gillespie, W.J.; Sherrington, C.; Gates, S.; Clemson, L.M.; Lamb, S.E. Interventions for preventing falls in older people living in the community. Cochrane Database Syst. Rev. 2012. [CrossRef]

10. Robinovitch, S.N.; Feldman, F.; Yang, Y.; Schonnop, R.; Leung, P.M.; Sarraf, T.; Sims-Gould, J.; Loughin, M. Video capture of the circumstances of falls in elderly people residing in long-term care: An observational study. Lancet 2013, 381, 47-54. [CrossRef]

11. Timsina, L.R.; Willetts, J.L.; Brennan, M.J.; Marucci-Wellman, H.; Lombardi, D.A.; Courtney, T.K.; Verma, S.K. Circumstances of fall-related injuries by age and gender among community-dwelling adults in the United States. PLoS ONE 2017, 12, e0176561. [CrossRef] [PubMed]

12. World Health Organization (WHO). World Report on Disability; WHO Press: Geneva, Switzerland, 2011; ISBN 978-92-4-156418-2.

13. Allen, N.E.; Schwarzel, A.K.; Canning, C.G. Recurrent falls in Parkinson's disease: A systematic review. Parkinson's Dis. 2013. [CrossRef] [PubMed]

14. Ambrosea, A.F.; Paula, G.; Hausdorff, J.M. Risk factors for falls among older adults: A review of the literature. Maturitas 2013, 75, 51-61. [CrossRef] [PubMed]

15. Deandrea, S.; Lucenteforte, E.; Bravi, F.; Foschi, R.; LaVecchia, C.; Negri, E. Risk Factors for Falls in Community-dwelling Older People: A Systematic Review and Meta-analysis. Epidemiology 2010, 21, 658-668. [CrossRef] [PubMed]

16. Lamb, S.E.; Jørstad-Stein, E.C.; Hauer, K.; Becker, C. Development of a Common Outcome Data Set for Fall Injury Prevention Trials: The Prevention of Falls Network Europe Consensus. J. Am. Geriatr. Soc. 2015, 53, 1618-1622. [CrossRef] [PubMed] 
17. Denkinger, M.D.; Lukas, A.; Nikolaus, T.; Hauer, K. Factors associated with fear of falling and associated activity restriction in community-dwelling older adults: A systematic review. Am. J. Geriatr. Psychiatry 2015, 23, 72-86. [CrossRef] [PubMed]

18. Kumar, A.; Carpenter, H.; Morris, R.; Iliffe, S.; Kendrick, D. Which factors are associated with fear of falling in community-dwelling older people? Age Ageing 2014, 43, 76-84. [CrossRef] [PubMed]

19. Kader, M.; Iwarsson, S.; Odin, P.; Nilsson, M.H. Fall-related activity avoidance in relation to a history of falls or near falls, fear of falling and disease severity in people with Parkinson's disease. BMC Neurol. 2016, 16, 84. [CrossRef] [PubMed]

20. Townsend, E.A.; Polatajko, H.J. Enabling Occupation II: Advancing an Occupational Therapy Vision for Health, Well-Being \& Justice through Occupation; CAOT Publications ACE: Ottawa, ON, Canada, 2007; ISBN 9781895437768.

21. Fänge, A.; Iwarsson, S. Changes in ADL dependence and aspects of usability following housing adaptation -A longitudinal perspective. AJOT 2005, 59, 296-304. [CrossRef] [PubMed]

22. Peterson, I.; Lilja, M.; Hammel, J.; Kottorp, A. Impact of home modification services on ability in everyday life for people ageing with disabilities. J. Rehabil. Med. 2008, 40, 253-260. [CrossRef] [PubMed]

23. Stark, S.; Keglovits, M.; Arbesman, M.; Lieberman, D. Effect of home modification interventions on the participation of community-dwelling adults with health conditions: A systematic review. AJOT 2017, 71, 7102290010p1-7102290010p11. [CrossRef] [PubMed]

24. Wahl, H.W.; Fänge, A.; Oswald, F.; Gitlin, L.N.; Iwarsson, S. The home environment and disability-related outcomes in aging individuals: What is the empirical evidence? Gerontologist 2009, 49, 355-367. [CrossRef] [PubMed]

25. Fänge, A.; Iwarsson, S. Changes in accessibility and usability in housing: An exploration of the housing adaptation process. Occup. Ther. Int. 2005, 12, 44-59. [CrossRef] [PubMed]

26. Keal, M.D.; Pierse, N.; Howden-Chapman, P.; Cunningham, C.; Cunningham, M.; Guria, J.; Baker, M.G. Home modifications to reduce injuries from falls in the home injury prevention intervention (HIPI) study: A cluster-randomised controlled trial. Lancet 2015, 385, 231-238. [CrossRef]

27. Ministry of Health and Social Affairs. The Housing Adaptation Act; SFS 1992:1547; Ministry of Health and Social Affairs: Stockholm, Sweden, 1992.

28. Chase, C.A.; Mann, K.; Wasek, S.; Arbesman, M. Systematic review of the effect of home modification and fall prevention programs on falls and the performance of community-dwelling older adults. AJOT 2012, 66, 284-291. [CrossRef] [PubMed]

29. Thordardottir, B.; Chiatti, C.; Ekstam, L.; Malmgren Fänge, A. Heterogeneity of characteristics amon housing adaptation clients in Sweden-Relationship to participation and self-rated health. Int. J. Environ. Res. Public Health 2016, 13, 91. [CrossRef] [PubMed]

30. Szanton, S.L.; Thorpe, R.J.; Boyd, C.; Tanner, E.K.; Leff, B.; Agree, E.; Xue, Q.-L.; Allen, J.K.; Seplaki, C.L.; Weiss, C.O.; et al. Community aging in place, advancing better living for elders: A bio-behavioral-environmental intervention to improve function and health-related quality of Life in disabled older adults. JAGS 2011, 59, 2314-2320. [CrossRef] [PubMed]

31. Fänge, A.; Iwarsson, S. Challenges in the development of strategies for housing adaptation evaluations. SJOT 2007, 14, 140-149. [CrossRef] [PubMed]

32. Malmgren Fänge, A.; Lindberg, K.; Iwarsson, S. Housing adaptations from the perspectives of Swedish occupational therapists. Scand. J. Occup. Ther. 2013, 20, 228-240. [CrossRef] [PubMed]

33. Ekstam, L.; Carlsson, G.; Chiatti, C.; Nilsson, M.; Malmgren Fänge, A. A research-based strategy for managing housing adaptations: Study protocol for a quasi-experimental trial. BMC Health Serv. Res. 2014, 14, 602. [CrossRef] [PubMed]

34. Boverket, National Board of Housing, Planning and Building. Bostadsanpassningsbidragen 2012, Housing Adaptation Grants 2012; Boverket, National Board of Housing, Planning and Building: Karlskrona, Sweden, 2013; no 34. (In Swedish)

35. Iwarsson, S.; Slaug, B. Housing Enabler. A Method for Rating/Screening and Analyzing Accessibility Problems in Housing; Wallin \& Dalholm: Lund, Sweden, 2010.

36. Freitas, S.; Simões, M.R.; Alves, L.; Vicente, M. Montreal Cognitive Assessment (MoCA): Validation Study for Vascular Dementia. J. Int. Neuropsychol. Soc. 2012, 18, 1031-1040. [CrossRef] [PubMed] 
37. Nasreddine, A.S.; Phillips, N.A.; Bédirian, V.; Charbonneau, S.; Whitehead, V.; Collin, I.; Cummings, J.L.; Chertkow, H. The Montreal Cognitive Assessment, MoCA: A Brief Screening Tool for Mild Cognitive Impairment. JAGS 2005, 53, 695-699. [CrossRef] [PubMed]

38. Sonn, U.; Asberg, K.H. Assessment of activities of daily living in the elderly. A study of a population of 76-years olds in Gothenburg, Sweden. Scand. J. Rehbil. Med. 1991, 23, 193-202. [PubMed]

39. Iwarsson, S.; Isacsson, A.; Lanke, J. ADL dependence in the elderly population living in the community: The influence of functional limitations and physical environmental demand. Occup. Ther. Int. 1998, 5, 173-193. [CrossRef]

40. Iwarsson, S.; Horstmann, V.; Sonn, U. Assessment of dependence in daily activities combined with a self-rating of difficulty. J. Rehabil. Med. 2009, 41, 150-156. [CrossRef] [PubMed]

41. Ministry of Enterprise and Innovation. The Swedish Planning and Building Act; SFS 2010:900; Ministry of Enterprise and Innovation: Stockholm, Sweden, 2010.

42. Gray, P.; Hildebrand, K. Fall risk factors in Parkinson's disease. J. Neurosci. Nurs. 2000, 32, 222. [CrossRef] [PubMed]

43. Kempen, G.I.; Yardley, L.; Van Haastregt, J.C.; Zijlstra, G.R.; Beyer, N.; Hauer, K.; Todd, C. The Short FES-I: A shortened version of the falls efficacy scale-international to assess fear of falling. Age Ageing 2008, 37, 45-50. [CrossRef] [PubMed]

44. Yardley, L.; Beyer, N.; Hauer, K.; Kempen, G.; Piot-Ziegler, C.; Todd, C. Development and initial validation of the Falls Efficacy Scale-International (FES-I). Age Ageing 2005, 34, 614-619. [CrossRef] [PubMed]

45. Xu, T.; Clemson, L.; O’Loughlin, K.; Lannin, N.A.; Dean, C.; Koh, G. Risk factors for falls in community stroke survivors: A systematic review and meta-analysis. Arch. Phys. Med. Rehabil. 2017. [CrossRef] [PubMed]

46. Medical Research Council (MRC). Developing and Evaluating Complex Interventions. 2008. Available online: www.mrc.ac.uk/complexinterventionsguidance (accessed on 15 September 2017).

47. Hannan, M.T.; Gagnon, M.M.; Aneja, J.; Jones, R.N.; Cupples, L.A.; Lipsitz, L.A.; Samelson, E.J.; Leveille, S.G.; Kiel, D.P. Optimizing the tracking of falls in studies of older participants: comparison of quarterly telephone recall with monthly falls calendars in the MOBILIZE Boston study. Am. J. Epidemiol. 2010, 171, 1031-1036. [CrossRef] [PubMed]

48. Scheffer, A.C.; Schuurmans, M.J.; van Dijk, N.; van der Hooft, T.; de Rooij, S.E. Fear of falling: Measurement strategy, prevalence, risk factors and consequences among older persons. Age Ageing 2008, 37, $19-24$. [CrossRef] [PubMed]

49. Kendrick, D.; Kumar, A.; Carpenter, H.; Zijlstra, G.A.R.; Skelton, D.A.; Cook, J.R.; Stevens, Z.; Belcher, C.M.; Haworth, D.; Gawler, S.J.; et al. Exercise for reducing fear of falling in older people living in the community. Cochrane Database Syst. Rev. 2014. [CrossRef]

50. Zijlstra, G.A.R.; Van Haastregt, J.C.M.; Van Rossum, E.; Van Eijk, J.T.; Yardley, L.; Kempen, G.I. Interventions to reduce fear of falling in Community-living older people: A systematic review. J. Am. Geriatr. Soc. 2007, 55, 603-615. [CrossRef] [PubMed]

51. Petersson, I.; Anders Kottorp, A.; Bergström, J.; Lilja, M. Longitudinal changes in everyday life after home modifications for people aging with disabilities. SJOT 2009, 16, 78-87. [CrossRef] [PubMed]

(C) 2017 by the authors. Licensee MDPI, Basel, Switzerland. This article is an open access article distributed under the terms and conditions of the Creative Commons Attribution (CC BY) license (http://creativecommons.org/licenses/by/4.0/). 